MATEC Web of Conferences 22,05003 (2015)

DOI: $10.1051 /$ matecconf/ 20152205003

(C) Owned by the authors, published by EDP Sciences, 2015

\title{
A Research and Implementation of Internal Medicine Diagnosis Assist- ed by Intelligence Knowledge Base
}

\author{
Xiaohui Zhang \\ Central Laboratory, Langfang Health Vocational College, Langfang, Hebei, China
}

\begin{abstract}
Intelligent knowledge system is an important knowledge base for internal medicine diagnosis. Intelligent diagnosis of the knowledge base can be realized by establishing appropriate expert models to assist diagnosis and treatment. By building the hierarchical model of internal diseases, this paper established an internal medicine diagnostic system assisted by intelligence knowledge base with the mathematical model of analytic hierarchy. The hierarchical model is able to summarize characteristics of diseases and quantize the determinant criterion of diseases. The weighted value of a possible disease can be obtained through the judgment of physicians on the weight of factors of the criterion layer and the compared calculation of database. It is concluded that the analytic hierarchy model can realize the auxiliary diagnosis function of intelligence knowledge base and the weight of a disease providing diagnostic reference for physicians.
\end{abstract}

Keywords: intelligent diagnosis; internal medicine; analytic hierarchy process; database; fuzzy recognition

\section{INTRODUCTION}

Nowadays, the pace of population aging in China is speeding up. It is now faced with a high morbidity brought by population aging in spite of the improvement of people's living standard. The overall medical level in China is undeveloped and imbalanced. Thus, the society must pay attention to the national health level. The population aging further increases the demand for medical services, medical facilities and diagnostic accuracy. It needs to be solved urgently in China that most rural areas and communities can have a convenient and high-quality hospital environment. Effective means of treatment can be realized by establishing a diagnostic database and diagnostic models. Internal medicine diagnosis provides patients with better services through the assistance of intelligence knowledge base and the judgment of physicians, and achieves the fast and accurate treatment.

Intelligent auxiliary diagnosis and treatment system is a system established on the basis of long-term experience and conclusion. This system provides physicians with all kinds of diagnosis and treatment results, judges and automatic analysis, and assists physicians when they diagnose. Establishing a correct mathematical model algorithm is an important part of the system in determining diagnostic results intelligently. In the 1970 s, a great deal of studies has been carried out in Chinese medical diagnosis. The "expert system of Chinese internal medicine diagnosis" is a key project of the state. Major mathematical models of the diagnostic system include fuzzy mathematics, neural network, and expert system and so on.

Based on previous studies, this paper carries out a study on the internal medicine diagnosis assisted by intelligence knowledge base. Patients can be treated with the use of the knowledge database and the mathematical model of hierarchical analysis. Physicians can rapidly finish diagnosis with the assistance of this system, realize process of matching diseases through quantized values of the mathematical model and provide physicians with assistance.

\section{MATHEMATICAL MODEL OF INTERNAL MEDICINE DIAGNOSIS}

Saaty, a famous American scholar, proposed a system of hierarchical mathematical analysis method which is combined with the quantitative and qualitative analysis and the subjective and objective analysis, namely the analytic hierarchy process (AHP). The core of the algorithm is the calculation of weight. It is especially suitable to solve multi-objective problems and decision problems of complex systems. The algorithm is a strong mathematical method that converts problems into quantitative studies. This paper will apply the system in internal medicine diagnosis; establish a model of hierarchical analysis for diagnosis, make data comparison through existing empirical data and express diagnostic results with quantized values so as to diagnose internal medicines. Characteristics of the analytic hierarchy process include simple ideas, distinct structure and wide range of application. The analytic hierarchy process has been widely used in various areas to solve practical problems. It can be divided into three processes: the establishment of hierarchical structure, the construction of judgment matrix, and the hierarchical ordering and consistency check. The flow chart of the calculation is shown in Figure 1. 


\section{MATEC Web of Conferences}

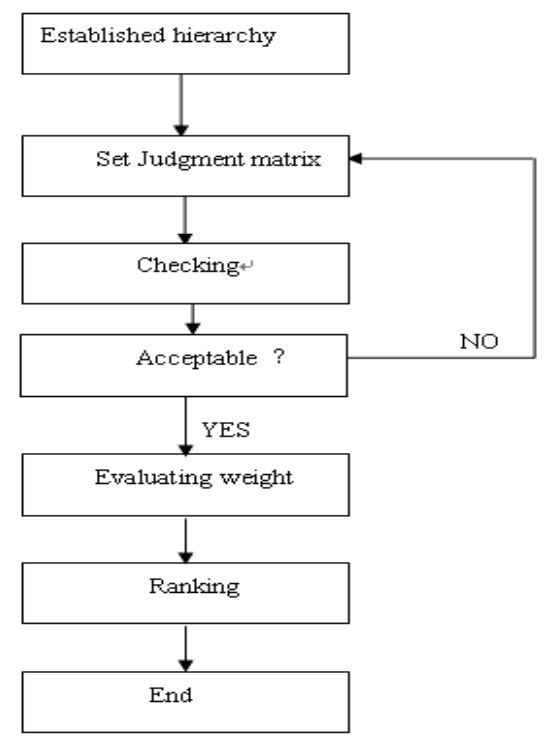

Figure 1. Logic diagram of hierarchical calculation.

Step-1 Establishment of hierarchical structure

There are usually three layers in a hierarchical structure of AHP. First, the objective layer (S) means the final goal or the final result of a problem. Second, the criterion layer $\left(f_{m}\right)$ means the requirement and standard of a problem. Third, the scheme layer $\left(p_{n}\right)$ means all methods for solving a problem.

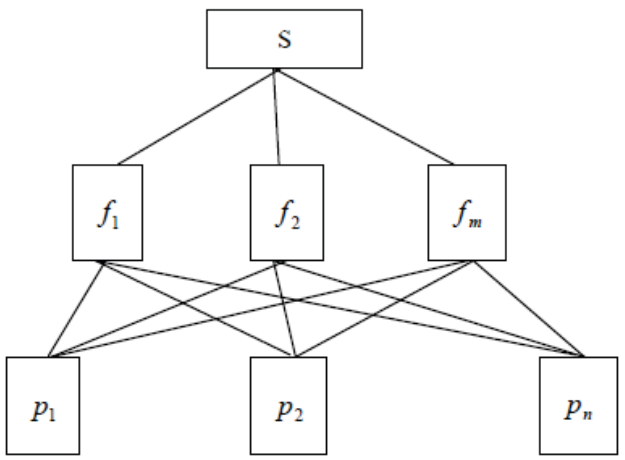

Figure 2. Structure of the analytic hierarchy process

Step-2 Construction of judgment matrix

It is supposed that there are $\mathrm{n}$ factors $C=\left(\begin{array}{llll}c_{1}, & C_{2} & \cdots & c_{1}\end{array}\right)$ of the next layer in a hierarchical structure having influence on objectives or criteria of the former layer. Thus, we make a comparison between any two factors and express the comparative results with quantized values. For example, the important comparison is made between $C_{i}$ and $C_{j}$, and the structure is expressed by $a_{i j}$. The judgment matrix A can be acquired after the comparison of all factors, which is expressed as follows.
Where, values of $a_{i j}$ are expressed with numbers from 1 to 9 and their reciprocals. After studies, Saaty believes that it is psychologically in accordance with people's judgment if scales from 1 to 9 are used to represent comparative structures. Meanings of numbers are provided in Table 1.

$$
A=\left(\begin{array}{cccc}
a_{11} & a_{12} & \cdots & a_{1 j} \\
a_{21} & a_{22} & \cdots & a_{2 j} \\
\vdots & \vdots & \ddots & \vdots \\
a_{i 1} & a_{i 2} & \cdots & a_{i j}
\end{array}\right)
$$

Table 1. Meanings of scales from 1 to 9

\begin{tabular}{ll}
\hline Scales & Meanings \\
\hline 1 & $\begin{array}{l}\text { Both factors are equally important } \\
\text { for the objective } \\
\text { The former factor is slightly more } \\
\text { important than the latter one } \\
\text { The former factor is more important } \\
\text { than the latter one } \\
5\end{array}$ \\
7 & $\begin{array}{l}\text { The former factor is more important } \\
\text { than the latter one } \\
\text { The former factor is extremely more } \\
\text { important than the latter one } \\
\text { The importance is between the two } \\
\text { uneven numbers } \\
\text { The order of positive and negative } \\
\text { comparisons of factors }\end{array}$ \\
\end{tabular}

Step-3 Consistency check and weight vector calculation

The definition of a uniform matrix: As for the ma$\operatorname{trix} A=\left(a_{i j}\right) \quad$, if elements satisfy $a_{i j} a_{i k}=a_{i k}$, the matrix is a uniform matrix. In this situation, $a_{i j}>0$ and $a_{i j}=1 / a_{j i}$. The inconsistency of the matrix is required to be acceptable in order to calculate the weight of factors. The consistency indicator of the judgment matrix is $\mathrm{CI}$ and the consistency ratio of the judgment matrix is CR. The calculation method is shown in the following formula:

$$
C I=\frac{\lambda_{\max }-n}{n-1}
$$

In this formula, $\mathrm{n}$ stands for the order of the judgment matrix, namely the number of comparing factors:

$$
C R=\frac{C I}{R I}
$$

Where, $R I$ stands for the value of Random Consistency Index, shown in the Table 2.

When $C R \geq 0.1$, the judgment matrix is inconsistent, it means that the judgment matrix needs to be adjusted. When $C R<0.1$, the inconsistency of the judgment matrix is within an acceptable range, which means that the next step of calculation can be proceeded so as to calculate the hierarchical total sequence and organize the consistency check. 
ICETA 2015

Table 2. Values of RI

\begin{tabular}{llllllllllll}
\hline $\mathrm{n}$ & 1 & 2 & 3 & 4 & 5 & 6 & 7 & 8 & 9 & 10 & 11 \\
\hline $\mathrm{RI}$ & 0 & 0 & 0.58 & 0.90 & 1.12 & 1.24 & 1.32 & 1.41 & 1.45 & 1.49 & 1.51 \\
\hline
\end{tabular}

Let us suppose that the value of $\mathrm{m}$ factors in layer $\mathrm{A}$ is $\alpha_{m}$, the corresponding consistency indicator is $C I_{m}$, and the weight of $\mathrm{n}$ factors of the layer $\mathrm{B}$ in layer $\mathrm{A}$ is $\beta_{n m}$, then the total ordering weight of the layer $\mathrm{B}$ is shown as follows:

$$
w_{i}=\sum_{j=1}^{m} \alpha_{i} \beta_{i j}
$$

The consistency ratio of the consistency check is shown as follows:

$$
C R=\frac{\sum_{j=1}^{m} \alpha_{j} C I_{j}}{\sum_{j=1}^{m} \alpha_{j} R I_{j}}
$$

There are many methods for the calculation of weight vectors of the judgment matrix, including the definition calculation, the computer iteration, the power method and the summation method. The summation method is relatively simple. Let us suppose that the weight vector of $\mathrm{n}$ factors of the judgment matrix is shown as follows:

$W=\left(w_{1}, w_{2}, w_{3} \cdots w_{n}\right)$

(1)The judgment matrix can be expressed as follows:

$A=\left(\begin{array}{cccc}w_{1} / w_{1} & w_{1} / w_{2} & \cdots & w_{1} / w_{n} \\ w_{2} / w_{1} & w_{2} / w_{2} & \cdots & w_{2} / w_{n} \\ \vdots & \vdots & \ddots & \vdots \\ w_{n} / w_{1} & w_{n} / w_{2} & \cdots & w_{n} / w_{n}\end{array}\right)$

Steps can be concluded according to the property of the matrix 1 . The matrix D can be obtained through the normalization of all column vector of A:

$D=\left(\begin{array}{cccc}a_{11} & a_{12} & \cdots & a_{1 n} \\ a_{21} & a_{22} & \cdots & a_{2 n} \\ \vdots & \vdots & \ddots & \vdots \\ a_{n 1} & a_{n 2} & \cdots & a_{n n}\end{array}\right) \bullet\left(\begin{array}{cccc}1 / \sum_{i=1}^{n} a_{i 1} & 0 & \cdots & 0 \\ 0 & 1 / \sum_{i=1}^{n} a_{i 2} & \cdots & 0 \\ 0 & \vdots & \ddots & \vdots \\ 0 & 0 & \cdots & 1 / \sum_{i=1}^{n} a_{i n}\end{array}\right)$

(2)The matrix E can be obtained by calculating the sum of each line of the matrix after normalization:

$E=D \bullet\left(\begin{array}{llll}1 & 1 & \cdots & 1\end{array}\right)_{1 \times n}^{T}$

$E=\left(\begin{array}{llll}e_{11} & e_{12} & \cdots & e_{1 n}\end{array}\right)^{T}$

(3) Normalization of the matrix E, namely the weight vector:

$W=\left(\begin{array}{llll}w_{1} & w_{2} & \cdots & w_{n}\end{array}\right)=\left(\begin{array}{llll}e_{11} / \sum_{i=1}^{n} e_{i 1} & e_{12} / \sum_{i=1}^{n} e_{i 1} & \cdots & e_{1 n} / \sum_{i=1}^{n} e_{i 1}\end{array}\right)$

(4) Calculation of the maximum eigenvalue:

$$
\lambda_{\max }=\frac{1}{n} \sum_{i=1}^{n} \frac{(A W)_{i}}{w_{i}}
$$

\section{AHP SIMULATION OF INTERNAL MEDICINE DIAGNOSIS}

In this paper, the target layer $(\mathrm{T})$ of the hierarchical model of internal medicine diagnosis is the illness condition diagnosis of patients. The criterion layer $(\mathrm{Cm})$ is the criteria for illness condition diagnosis and symptoms of patients. The scheme layer refers to potential diseases of patients. The hierarchical structure is established according to Table 1 which is shown in Figure 3. The simulation is conducted with four factors of criterion and five diseases.

\subsection{Weight calculation on the criterion layer}

According to the hierarchical structure in Figure 3, we will construct a judgment matrix and calculate the weight of criterion and consistency check indicators. Results are shown as follows:

Table 3. Calculation results of the criterion layer

\begin{tabular}{|l|l|l|l|l|l|}
\hline$T$ & $C_{1}$ & $C_{2}$ & $C_{3}$ & $C_{4}$ & $C_{5}$ \\
\hline$C_{1}$ & 1 & 4 & 4 & 3 & 2 \\
\hline$C_{2}$ & $1 / 4$ & 1 & 1 & $1 / 2$ & $1 / 2$ \\
\hline$C_{3}$ & $1 / 4$ & 1 & 1 & $1 / 2$ & $1 / 3$ \\
\hline$C_{4}$ & $1 / 3$ & 2 & 2 & 1 & $1 / 3$ \\
\hline$C_{5}$ & $1 / 2$ & 2 & 3 & 3 & 1 \\
\hline$W$ & 0.409 & 0.096 & 0.088 & 0.146 & 0.260 \\
\hline$\lambda$ & 5.116 & \multicolumn{5}{|l|}{} \\
\hline$C R$ & 0.026 \\
\hline
\end{tabular}

3.2 It can be concluded that $C R<0.1$ from the aforementioned results and the matrix is checked as well.Determination of the weight of the scheme layer and implementation scheme

According to the importance of different schemes on the criterion layer, we construct a judgment matrix and carry out the consistency check. Afterwards, we calculate the weight of the scheme layer and use a reasonable method of implementation. The test value of each judgment matrix is $C R<0.1$, and the consistency test value combined is $C R<0.1$. 


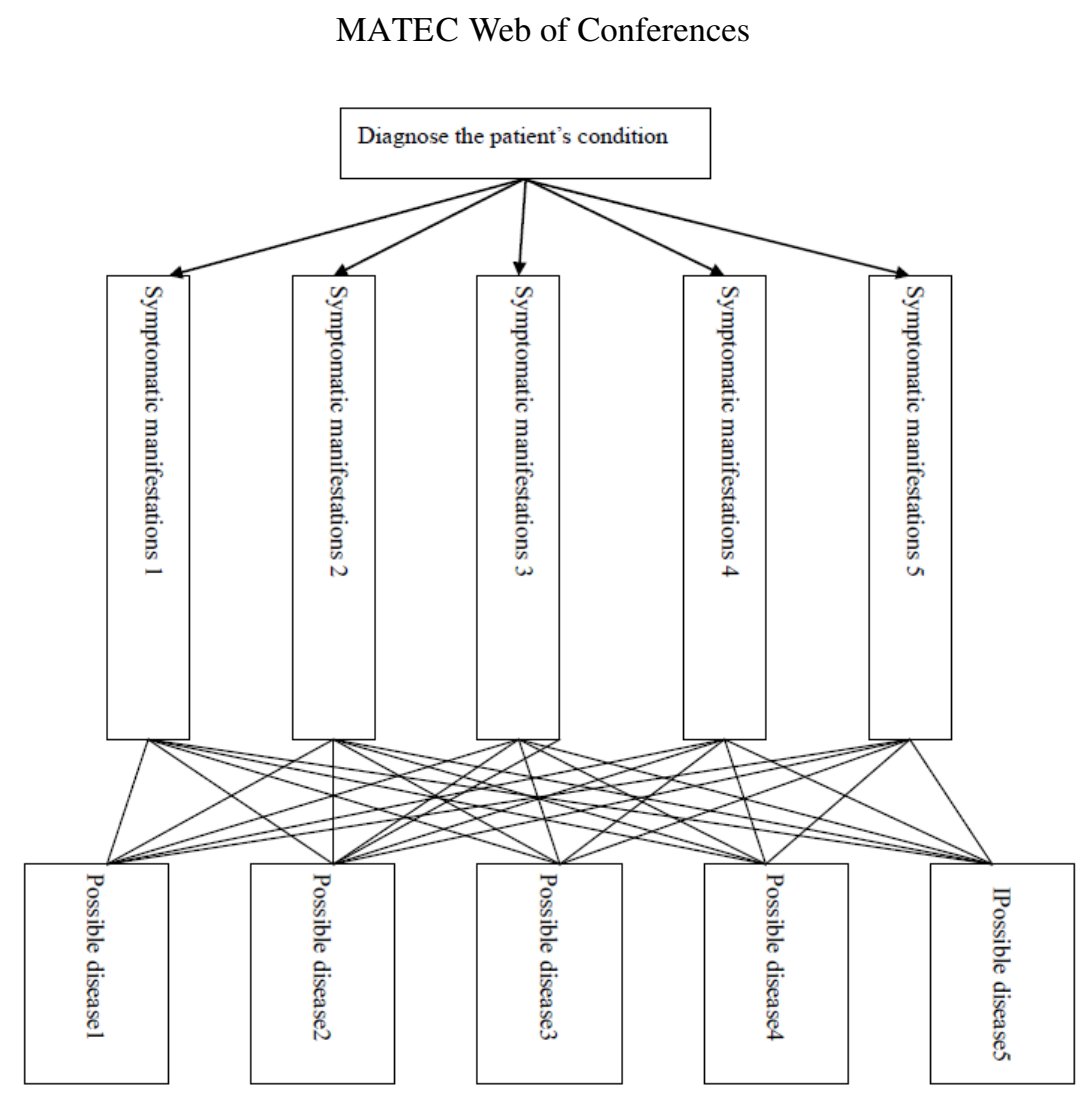

Figure 3. Thee hierarchical structures of the diagnosis system

Table 4. Importance of weight of scheme $\mathrm{P}$ for the criterion $\mathrm{C} 1$

\begin{tabular}{|l|l|l|l|l|l|}
\hline$C_{1}$ & $P_{1}$ & $P_{2}$ & $P_{3}$ & $P_{4}$ & $P_{5}$ \\
\hline$P_{1}$ & 1 & 7 & 3 & 8 & 2 \\
\hline$P_{2}$ & $1 / 7$ & 1 & $1 / 3$ & 1 & $1 / 3$ \\
\hline$P_{3}$ & $1 / 3$ & 3 & 1 & 2 & $1 / 2$ \\
\hline$P_{4}$ & $1 / 8$ & 1 & $1 / 2$ & 1 & $1 / 4$ \\
\hline$P_{5}$ & $1 / 2$ & 3 & 2 & 4 & 1 \\
\hline$W$ & 0.474 & 0.066 & 0.150 & 0.065 & 0.245 \\
\hline$\lambda$ & 5.04 & 0.009 & \\
\hline$C R$ & 0.9 & \\
\hline
\end{tabular}

Table 5. Importance of weight of scheme $\mathrm{P}$ for the criterion $\mathrm{C} 2$

\begin{tabular}{|l|l|l|l|l|l|}
\hline$C_{2}$ & $P_{1}$ & $P_{2}$ & $P_{3}$ & $P_{4}$ & $P_{5}$ \\
\hline$P_{1}$ & 1 & $1 / 6$ & 2 & $1 / 2$ & $1 / 4$ \\
\hline$P_{2}$ & 6 & 1 & 9 & 4 & 2 \\
\hline$P_{3}$ & $1 / 2$ & $1 / 9$ & 1 & $1 / 3$ & $1 / 5$ \\
\hline$P_{4}$ & 2 & $1 / 4$ & 3 & 1 & $1 / 2$ \\
\hline$P_{5}$ & 4 & $1 / 2$ & 5 & 2 & 1 \\
\hline$W$ & 0.077 & 0.481 & 0.047 & 0.135 & 0.260 \\
\hline$\lambda$ & 5.03 & & & & \\
\hline$C R$ & 0.006 &
\end{tabular}


ICETA 2015

Table 6. The importance weight of scheme $\mathrm{P}$ for the criterion $\mathrm{C} 3$

\begin{tabular}{|l|l|l|l|l|l|}
\hline$C_{3}$ & $P_{1}$ & $P_{2}$ & $P_{3}$ & $P_{4}$ & $P_{5}$ \\
\hline$P_{1}$ & 1 & $1 / 2$ & $1 / 5$ & 3 & 1 \\
\hline$P_{2}$ & 2 & 1 & $1 / 2$ & 5 & 3 \\
\hline$P_{3}$ & 5 & 2 & 1 & 9 & 5 \\
\hline$P_{4}$ & $1 / 3$ & $1 / 5$ & $1 / 9$ & 1 & $1 / 2$ \\
\hline$P_{5}$ & 1 & $1 / 3$ & $1 / 5$ & 2 & 1 \\
\hline$W$ & 0.115 & 0.249 & 0.491 & 0.048 & 0.096895 \\
\hline$\lambda$ & 5.03 & & \\
\hline$C R$ & 0.007 &
\end{tabular}

Table 7. Importance of weight of scheme $\mathrm{P}$ for the criterion $\mathrm{C} 4$

\begin{tabular}{|l|l|l|l|l|l|}
\hline$C_{4}$ & $P_{1}$ & $P_{2}$ & $P_{3}$ & $P_{4}$ & $P_{5}$ \\
\hline$P_{1}$ & 1 & $1 / 3$ & 3 & $1 / 4$ & 3 \\
\hline$P_{2}$ & 3 & 1 & 5 & $1 / 2$ & 5 \\
\hline$P_{3}$ & $1 / 3$ & $1 / 5$ & 1 & $1 / 8$ & 1 \\
\hline$P_{4}$ & 4 & 2 & 8 & 1 & 7 \\
\hline$P_{5}$ & $1 / 3$ & $1 / 5$ & 1 & $1 / 7$ & 1 \\
\hline$W$ & 0.134 & 0.287 & 0.054 & 0.470 & 0.055442 \\
\hline$\lambda$ & 5.06 & \multicolumn{7}{l}{} \\
\hline$C R$ & 0.014 &
\end{tabular}

Table 8. Importance of weight of scheme $\mathrm{P}$ for the criterion C5

\begin{tabular}{|l|l|l|l|l|l|}
\hline$C_{5}$ & $P_{1}$ & $P_{2}$ & $P_{3}$ & $P_{4}$ & $P_{5}$ \\
\hline$P_{1}$ & 1 & 3 & 5 & 7 & $1 / 3$ \\
\hline$P_{2}$ & $1 / 3$ & 1 & 2 & 2 & $1 / 9$ \\
\hline$P_{3}$ & $1 / 5$ & $1 / 2$ & 1 & 3 & $1 / 6$ \\
\hline$P_{4}$ & $1 / 7$ & $1 / 2$ & $1 / 3$ & 1 & $1 / 9$ \\
\hline$P_{5}$ & 3 & 9 & 6 & 9 & 1 \\
\hline$W$ & 0.258 & 0.088 & 0.076 & 0.040 & 0.538549 \\
\hline$\lambda$ & 5.233 & & & \\
\hline$C R$ & 0.052 &
\end{tabular}

Therefore, the consistency of the AHP judgment matrix is in accordance with the calculation requirement. Then we calculate the final weight of the scheme through the hierarchical total order. And results are shown in the table as follows:

Table 9. Total weights of the scheme layer

\begin{tabular}{|c|c|c|c|}
\hline $\begin{array}{l}\text { Target } \\
\text { layer }\end{array}$ & $\begin{array}{l}\text { Scheme } \\
\text { layer }\end{array}$ & Weights & $\begin{array}{l}\text { Weight ordering } \\
\text { of the scheme }\end{array}$ \\
\hline \multirow{5}{*}{$\begin{array}{l}\text { Internal } \\
\text { medicine } \\
\text { disease } \\
\text { diagnosis }\end{array}$} & $\begin{array}{l}\text { Possible } \\
\text { disease } 1\end{array}$ & 0.29 & 1 \\
\hline & $\begin{array}{l}\text { Possible } \\
\text { disease } 2\end{array}$ & 0.17 & 3 \\
\hline & $\begin{array}{l}\text { Possible } \\
\text { disease } 3\end{array}$ & 0.15 & 4 \\
\hline & $\begin{array}{l}\text { Possible } \\
\text { disease } 4\end{array}$ & 0.17 & 3 \\
\hline & $\begin{array}{l}\text { Possible } \\
\text { disease } 5\end{array}$ & 0.27 & 2 \\
\hline
\end{tabular}

In the internal medicine disease diagnosis of AHP, the calculation results of AHP suggest that the possibility of disease 1 is 0.29 , the possibility of disease 2 is 0.17 , the possibility of disease 3 is 0.15 , the possibility of disease 4 is 0.17 and the possibility of disease 5 is 0.22 . Disease 1 and disease 2 are diseases that need to be considered with more attentions. With the judgment of symptoms, physicians are able to obtain suggestions by inputting symptoms into the system. The mathematical model of AHP can be applied in the intelligence knowledge base to assist internal medicine diagnosis.

\section{CONCLUSION}

In the realization of the internal medicine diagnosis system assisted by intelligence knowledge base, the analytic hierarchy process can be perfectly used to 


\section{MATEC Web of Conferences}

calculate symptoms of patients through quantized values so as to calculate final diseases. In AHP, it is required to set weight values of symptoms in different diseases through previous experience that are taken as the knowledge base, therefore, the knowledge in experience database can be rapidly adjusted by the system in a diagnosis and calculate weight values of patients' symptoms. And weight values of symptoms can also provide physicians with experiences and suggestions in a diagnosis.

\section{REFERENCES}

[1] Wang, Y.Y., Wang, F. \& Yang, H. 2011. Application of hermeneutics in internal medicine of traditional Chinese medicine, Journal of Traditional Chinese Medicine, 52, 7

[2] Teng, W.L. 2013. Research and Design of the Medical Diagnostic System Based on Artificial Intelligence, Jilin: Jilin University.

[3] Liu, L.Y. 2013. A brief discussion on clinical research of internal medicine of traditional Chinese medicine, China News of Traditional Chinese Medicine, 11: 20.

[4] Gao, L., Bu, H.Y. \& Hu, S. 2002. Design and implementation of an inference engine of medical and intelligent diagnosis, Computer Applications and Software, 6 : 44-46.

[5] Li, J. \& Lu, H.X. 2004. Design and implementation of an inference engine of the medical diagnosis expert system, Microcomputer Development, 14(9): 45-46.

[6] Luo, S.L. 2012. A Study on the Fuzzy Expert System Based on Medical Diagnosis, Hunan: Hunan University.

[7] Ma, R. 2009. Research and Implementation of Diagnostic Knowledge Base Management Assisted by Intelligent Medical Science, Sichuan: Southwest Jiaotong University. 